\title{
K-Conjecture- The Future of Biology
}

\author{
Kass L* \\ School of Biology \& Ecology, University of Maine, USA \\ *Corresponding author: Leonard Kass, Ph D, School of Biology and Ecology, \\ University of Maine, Orono, ME 04469 USA, Email: leonard.kass@maine.edu
}

\section{Editorial \\ Volume 1 Issue 5}

Received Date: October 17, 2018

Published Date: October 26, 2018

DOI: $10.23880 /$ izab-16000126

\section{Editorial}

In all modern-day republics and democracies, science investigations depend upon the support of the general public. These citizens will continue to support future science research if they remain acquainted with and appreciative of its basic methods, capabilities, achievements and aspirations. Science education is needed to inform and excite the public about the findings and benefits gained from scientific study, as well as to prepare the next generation of citizens for careers as practicing scientific professionals. Understanding science is critical for humanity to advance best practice in health, education, industry, and social policy. But through what route is science education best achieved?

Formalized class work in schools is the standard educational vehicle through which most citizens first become familiar with science. Students world-wide take courses in biology during their formal school years. Many students also might engage in additional science disciplines, like in chemistry, physics, and earth science. But, after 12 or so years of such formal schooling, during which only one science class per year might be taken, this minimal science education ends for all but the very few. This decade of formal learning, though formative, may be the only science exposure for most people. Worse still, for future science support, citizens vote for many years after this brief early exposure. Depending upon the quality of their schools and teachers, the inspirations once felt from experiencing science will diminish over time, unless rejuvenated. But what, then, can sustain enthusiasm for science once citizens are out of school and no longer exposed formally to its wonders?

Post formal education, most people obtain science information from a variety of popular sources. Television, smart phone, personal computer (PC), and cinematic theatre are main tools used by most free citizens today for learning about the world around them. For science to continue to inspire its complex and aging citizenry, those who would promote science must adapt to and utilize these new media. The cinematic movie is an innovative media ever growing in popularity today. Market research indicates that over two-thirds of all citizens in the USA and Canada watch at least one film a year in theaters [1]. Of all top box office hit movies released within the last 10 years, over half were science-fiction (SciFi) related films [2]. Ten of the top $12 \mathrm{SciFi}$ films of all time have been released within the past decade [3]. The point made here is that a large part of the general public's non-school exposure to science-related topics is through SciFi film, a media increasing in popularity and extending beyond the theater onto a multitude of platforms (e.g. Netflix, Hula, HBO, etc.). As a professional community of scientists concerned with the future of biology and science education, as well with the general public's best interest at heart, we might better promote good science within the SciFi genre rather than ignore or denigrate its use and popularity. But how best can authentic and exciting modern science are imbued into main stream SciFi?

I introduce here the K-Conjecture as an example of how a "futuristic" biological outcome could become popular within the SciFi community. If adapted by the SciFi world, it would help update and educate the public in the areas of evolution, ecology, and neuroscience. The "Weak Form" of the K-Conjecture states that humans (H. sapiens sapiens) have reached a plateau in intelligence and will not evolve further into a more highly intelligent animal. The "Strong Form" of the K-Conjecture states that no biological creatures, anywhere in the universe, can reach an intelligence level higher than that of human capability on Earth. The K-Conjecture runs counter to assumptions currently made in SciFi literature and cinema that portray vastly superiorly evolved aliens. At first glance, the K-Conjecture might appear counterintuitive to the scientific community. The premises that underlie and support the K-Conjecture incorporate various accepted biological concepts and principles. One 


\section{International Journal of Zoology and Animal Biology}

such ecological principle involves "K-selective" (in contrast to "r-selective") species. Since the K-Conjecture holds only for a specific type of K-selective species, it has been so named. The letter ' $\mathrm{K}$ ' in science is also associated with equilibria, carrying capacities, and constants incorporated into the K-Conjecture. I hope and expect that future use of the K-Conjecture within the SciFi and general public communities will disseminate concepts and principles of biology important to evolution, selective driving forces, and animal behaviors.

The K-Conjecture is a falsifiable hypothesis on the limits of achievable intelligence of humans, as well as all other biologically evolved creatures. Before presenting the $\mathrm{K}$-Conjecture premises, it is essential to understand what the K-Conjecture does not presume. It does not argue nor suggest that humans will not further evolve. Indeed, one single pandemic affliction of humans, if severe enough, can readily cause significant changes in gene frequencies worldwide and thereby drive human evolution. However, as argued below, such afflictions will not selectively increase innate human intelligence. The KConjecture does not argue that we will not continue to advance our accumulated knowledge, and cultural evolution, through "memes" or through other means [4]. Neither does the K-Conjecture rule out some future advanced artificial intelligence (AI) achieving higher levels of intelligence than human capabilities on Earth or elsewhere in the universe. The K-Conjecture addresses net average intelligence of a population, not subpopulations within an entire gene-pool.

The two major premises that form the foundation of the K-Conjecture involve the loss of external evolutionary drivers towards higher intelligence, and innate factors linked with human level intelligence (HLI). (i) A biological species that evolves into one with HLI becomes, over time, either (a) extinct, or (b) dominant within its world. If the HLI becomes extinct, the K-Conjecture is not falsified. If they dominate, selective pressure towards higher intelligence will no longer be exerted upon them from outside inter-specie competition and selection. (ii) For the "winning" HLI dominant specie, other innate behaviors, directly-linked to HLI properties, come into play and thereby preventing intra-species HLI selection towards higher intelligence of the species. If the above two premises are true, then there will neither be outside (Premise 1) nor inside (Premise 2) selective drivers towards higher intelligence of the HLI species. The KConjecture thereby will be sustained. Let us now examine each of these two premises in turn.

HLIs have behaviors uncommon to non-HLI species.
Over time, humans have used their intellectual powers to learn, innovate, experiment, communicate, record, and accumulate an exponentially growing knowledge base across generations and millennia. These special attributes of the HLI nervous system have allowed humans to dominate other non-HLI species in every biome worldwide. Before becoming the dominant species on Earth, proto-human species interbred with the Neanderthals (Homo neanderthalensis) and Denisovans (Homo sapiens denisova), before their extinctions, or rather their partial consolidations [5-7]. There is no evidence that either of those two Hominids were of such superior intelligence to HLIs, so as to be exceptions to the $\mathrm{K}$-Conjecture. Now that $\mathrm{H}$. sapiens sapiens is the dominant and sole HLI species on Earth, one cannot identify an external selective pressure that would drive humans towards evolving into a more intelligent species. Evolution is all about selective drivers for a particular trait; even an infinite amount of available time will not alter gene frequencies [8-10]. This is a key aspect of evolution that non-biologists often misunderstand. Hardy-Weinberg Equilibria form the main building blocks of both Weak and Strong Forms of the K-Conjecture, as will be further elaborated.

A predator or pathogen, to negate the K-Conjecture, would have to selectively kill (or selectively decrease reproductive capacity of) the less intelligent members of a significant number of the HLI population over many generations. The probability of an HLI species evolving on any given world is diminishingly low, perhaps only one or several per galaxy [11]. Multiplying that small probability by an even diminishingly smaller probability of a pathogen (never before postulated) that specifically selects for lower intelligence in an HLI population, indicates the infeasibility of a predator or pathogen increasing the intelligence of he dominant HLI species. Further, that possibility can be precluded since the probability of a predator or pathogen being effective in bringing the HLI species to extinction, regardless of intelligence level, will be many orders of magnitude higher in probability than its alternative. In addition, it would be expected that that any pathogen specific for intelligence would far more likely, by orders of magnitude, to diminish the intelligence of the HLI survivors than improve it. This expectation is based upon the presumed enhanced neural complexity underlying the more intelligent variants within a population of HLIs. From these arguments, we may conclude that no reasonable external threat will evolve the HLI species into a different one of greater intelligence. This conclusion derives from the non-selectivity of externally applied evolutionary drivers towards greater intelligence in an HLI species. 


\section{International Journal of Zoology and Animal Biology}

The HLI species will also not increase in intelligence by artificially selecting for or against specific members within its own population. Examples of such intra-species HLI artificial selective behaviors include genocide/eugenics and other lethal conflicts. Contrary to the expectations of some, these behaviors have not lead, nor will they lead, to any net increases in intelligence among HLI species. The reasons why require us to review evolution and the necessary social concomitants of the HLI brain.

Misconceptions of human evolution lead to misunderstanding elements supporting the K-Conjecture. The hallmark of Earth's only existent HLI species ( $\mathrm{H}$. sapiens sapiens) is its facility for dealing with abstract and complex symbols, logic, and language. Smith and Szathmáry [12,13] designate only humans as an 8th Transition species, the only single example of its emergence after seven prior major evolutionary transitions over Earth's history. This follows the general tenants of "Punctuated Equilibrium" first proposed by Eldredge and Gould [14,15]. Darwin envisioned more smooth or gradual evolutionary change from one species, family, phylum, or even kingdom from one to the other [16]. Margulis exemplified Punctuated Equilibrium on a large scale by illuminating the transition from prokaryotes to eukaryotes (Smith and Szathmáry's 4th major transition) [17]. One of the major evolutionary processes through which the 7th major transition (solitary individuals to colonies) became the 8th (primate societies to human societies) was through neoteny [18]. This particularly slow development of brain and body development in human infants and juveniles requires bonding and parental care for a decade or longer. To support this new biological need, without becoming extinct, the human brain evolved to be highly social as well as intelligent. It may be that "social intelligence" is as important as "analytical intelligence" that primarily is measured by standardized "Intelligence Quotient" (IQ) testing [19]. It also may be that the acquisition and facility with language is the defining character of the HLI brain ever since evolved by our ancestors about 50,000 years ago [20]. Appreciating the importance of social intelligence towards successful HLI emergence and its continued survival on Earth, and the abrupt or punctuated change necessary for significant evolutionary change, are both critical towards understanding the arguments underlying the K-Conjecture.

A species with a solely analytical and scientific brain can be dangerous to its world and itself. In humans, the last 100 years has brought numerous deaths through wars and conflicts, together with various environmental catastrophes on world-wide levels. The sheer scale of human-made disasters is magnified by technological advances made possible by, and only by, an HLI brain. Human history has always included inter-tribal conflicts and wars. But these social pathologies, and other related atrocities that include genocide and eugenics, are typically committed against individuals and groups outside of one's own tribe. One's tribe might include their family, town, religion, country, or other group of social belonging. A psychopath can be considered a tribe of one. Purposeful human mistreatments of each other are inter-tribal. However, within the tribe there are strict rules to ensure mutualistic behaviors. Especially protected are newborns and juveniles. Inter-tribal killings, and other means to prevent or reduce reproductive success, are not directed in a way to benefit the intellectually gifted that remains outside one's tribe. Therefore, inter-tribal injustices have not and will not increase the intelligence of $\mathrm{H}$. sapiens sapiens. Within the tribe, all young are cared for to the best of the tribe's abilities, and therefore no evolution with regards to intelligence can be expected. The KConjecture is thusly supported.

Sexual selection could, in principle, lead to an increase in net human intelligence over time, thereby possibly providing an argument against the validity of the $\mathrm{K}$ Conjecture. But there is no evidence for any net positive effect of sexual selection on HL and strong reason to doubt its practicality within human society. The leading drivers for sexual selection in humans appear to be masculinity/femininity, odor, facial attractiveness related to positional symmetry, color, interest shown to the selector, scarification, lack of parasites, youth, waist-tohip ratio, dependability, size and color of lips, age, and breast or muscle sizes [21-30]. Nowhere in the literature is there a direct correlate with intelligence. In some individuals, there is an attractiveness factor associated with the potential mate having resources (money, education, employment) that may be weakly correlated with a modest level of intelligence. Such access to conspicuous resources may have much more to do with nepotism, favoritism, and other fortuitous circumstances. Sustained and accumulated personal wealth may be highly correlated with greed, avarice, and other antisocial behaviors within an individual or family. Whatever the case may be, any sexual selection in humans based upon any weak correlate to intelligence is negated when considering that all interested parties can find a partner and reproduce if so desired. Moreover, there is evidence to support the findings that more intelligent humans tend to have fewer children on average [31-35]. This negative correlation between intelligence and number of offspring would run counter to an increase in human intelligence over time. 


\section{International Journal of Zoology and Animal Biology}

The "Weak Form" of the K-Conjecture that human intelligence will not increase over time is supported by logic and available evidence. As was presented above, no evidence for external (outside of humanity) nor internal (human effects on other humans) drivers of higher human intelligence exist. Historical evidence from past millennia supports the K-Conjecture. Indeed, the mathematics and science used in engineering the Egyptian pyramids four and a half millennia ago seems so beyond HLI capacity, that even college-educated students believe their builders to be extraterrestrial aliens [36,37]. There are histories about ancient Africans, Greeks, Persians, Chinese, Mayans, and others that provide ample evidence that humans today are no more intelligent than our ancestors. Plato, a Western philosopher from the 4th century BCE, is still relevant today. Even important esteemed philosophers have stated that the safest general characterization of the European philosophical tradition is that it consists of a series of footnotes to Plato [38]. The "Weak Form" of the $\mathrm{K}$-Conjecture, to state it in other words, proposes that an average human baby today would, on average, perform no better and no worse than the average human baby from millennia past or future, if the same environmental conditions were provided to that average baby. The theoretically average "innate" intelligence in H. sapiens sapiens babies over millennia is what the K-Conjecture maintains has remained constant. The average human individual will survive and reproduce equally well depending upon the environmental conditions into which they are conceived, at least since the agricultural revolution and the establishment of large human population centers.

The "Strong Form" of the K-Conjecture, that no evolved HLI species anywhere in the universe can and will surpass HLI, will be addressed next. The "Weak Form" of the K-Conjecture may seem obvious to many educated in Hardy-Weinberg Equilibria $[9,10]$ and familiarity with the necessary drivers of evolutionary change. However, support for the "Strong Form" of the KConjecture, that the highest intelligence level biologically evolving anywhere in the Universe cannot surpass this planet's HMI, may not be so obvious. Further discussion is required to explore its foundation.

I begin by assuming that the physical laws are everywhere the same in the universe. And that chemistry and geology will work on other worlds as it does on Earth, given matched environmental conditions. Biology is applied physics, nothing more nor less than that. Evolutionary history will follow its separate trajectory, but its general principles will be the same. If life had to restart on Earth, it would take a different pathway, but its principles and general processes would be the same. For example, the first change from non-life (chemistry) to life (biology) is assumed to be a process governed by the Laws of Thermodynamics [39-50]. To begin the evolutionary process into life of ever more complex forms, one needs only a replicator. The replicators can be crystals, clays, or other self-organizing chemicals and materials. Once an entity is capable of sustaining replication, evolution is off and running. Life on other worlds will not necessarily proceed through the same 7 major transitions referred to above, before possibly leading to an HLI species. However, on those assumed rare occasions that an HLI species does evolve elsewhere in the universe without becoming extinct, one can describe its various general and necessary characteristics.

One trait that all HLI species will have in common is that they will have complex brains. They each will have an evolutionary history that began with the simplest of ancestors that we can call a "cell", though its metabolic and replicative processes may be quite different from the cells evolved on Earth. The alien HLI species will be made of these cells because of the fundamental nature of evolutionary processes. These cells will be arranged into various tissue types. Its cells, tissues, and organs will be specialized within the HLI species for metabolism, reproduction, protection, communication, and so on, for survival and reproductive success. Its major communication organ, which we can call its brain, will possess HMI properties. The ancestral line to the HLI species would have first included r-selective species: fast developing requiring no or minimal parental care because these types are evolutionarily simpler and therefore precedent. But for the evolved HLI species, it will have to be K-selective: slow developing and requiring protracted protection and nurturing while in its juvenile stage. To survive as a species, it must have evolved through a "Kselective Life History Strategy". K-selected species display traits associated with living at densities close to carrying capacity and typically are strong competitors in such crowded niches that invest more heavily in fewer offspring, each of which has a relatively high probability of surviving to adulthood. As used by humans, this biological strategy for survival incorporates strong norms and strictures against harming its infants and juveniles. Any HLI brain can use symbolic logic with capacities for viewing its world, and those within it, abstractly. Any alien HLI species will have the capacity to reason as social humans do: that A should treat B as B treats A, with A and $B$ assigned arbitrarily to the individual or its tribal neighbor. We can assume that mathematics and logic are everywhere the same, throughout the universe. A universal exercise in symbolic reasoning forms the basis of all "Golden Rules" of morality, Do onto others (e.g. B) as you would have them do onto you (e.g. A), is easily 


\section{International Journal of Zoology and Animal Biology}

performed reasoning for any HLI species, having evolved with a K-selective strategy, elsewhere in the universe. It will also form the basis of all ethical systems. For the longterm survival of any HLI species, it would necessarily have evolved that modest degree of empathy within its tribe, as was the case discussed above with humans.

With regards to the K-Conjecture, the conclusions reached with alien HLI species are similar to the ones obtained with humans. There will be opportunity within the tribe, and protection of all cooperating members, to the extent that intelligence will not be specifically selected for nor against. Therefore, there will be no further improvements in net intelligence within any alien species thusly endowed beyond the HLI limit or plateau. The reasoning underlying the "Strong Form" of the KConjecture is, thereby, concluded.

What, now, should be done with the K-Conjecture? To what good service might it be applied? Since science is a process and not a finished product, scientists ought to be concerned with the advancement of their profession. Failure to appreciate findings from scientific research leads to climate change and various forms of toxic and maladaptive environmental policies. Earth could become unsuitable for life. That would lead to the end of biology as we know it. Environmental degradation and conflicts retard science research for many political, social, and economic reasons. With our future in mind, biologists must say and do more, both within and outside of their professional circles. Social problems are more closely related to biology than they are to any of the other areas of science. That suggests that biologists should play a larger role in finding short and long-term solutions to problems. One key approach lies in educating the general public about the biological processes underlying these social and environmental problems. Unfortunately, the voting public is almost entirely finished with their formal education. Too many citizens find the teaching of science too dry or difficult. Therefore, other indirect or alternate routes must be explored to educate the voting public. SciFi may be one such alternate entrance. As referenced in the opening paragraphs, SciFi is extremely popular and gaining viewership from year to year. If more scienceminded individuals became engaged in writing SciFi stories and movie scripts, SciFi could provide better alternatives to pseudoscience and pure fantasy. SciFi could enter the realm of scientific possibility and future discovery. The K-Conjecture incorporates exciting and thought-provoking findings from evolution, ecology, paleontology, anthropology, and behavioral sciences. It injects valid science into the SciFi world. The KConjecture reflects upon the true nature of humanity, its behaviors and biological future. How well the public is educated in biology will determine Earth's future. Perhaps, then, SciFi has become too important to be left entirely in the hands of non-biologists.

\section{Acknowledgement}

The author thanks Drs. Richard Kass, Janice L. Pelletier, and Michael Wieder for reading this piece and for providing their thoughtful suggestions.

\section{References}

1. Global (2012) Theatrical Market Statistics.

2. Adam Hayes (2014) Top Grossing Sci-Fi Films of All Time. Investopedia.

3. Dawkins R (1989) The Selfish Gene 2nd (Edn.), Oxford University Press pp: 192.

4. Sankararaman S, Mallick S, Dannemann M, Prüfer K, Kelso J, et al. (2014) The genomic landscape of Neanderthal ancestry in present-day humans. Nature 507(7492): 354-357.

5. Vernot B, Akey JM (2014) Resurrecting Surviving Neandertal Lineages from Modern Human Genomes. Science 343(6174): 1017-1021.

6. Krause J, Fu Q Good JM, Viola B, Shunkov MV, et al. (2010) The complete mitochondrial DNA genome of an unknown hominin from southern Siberia. Nature 464 (7290): 894-897.

7. Castle WE (1903) The laws of Galton and Mendel and some laws governing race improvement by selection. Proceedings of the American Academy of Arts and Sciences. 39(8): 233-242.

8. Hardy GH (1908) Mendelian Proportions in a Mixed Population. Science 28 (706): 49-50.

9. Weinberg W (1908) Über den Nachweis der Vererbungbeim Menschen. Jahreshefte des Vereinsfürvaterländische Naturkunde in Württemberg 64: 368-382.

10. Ward PD, Brownlee DE (2000) Rare Earth: Why Complex Life Is Uncommon in the Universe Rare Earth. Copernicus Publishers pp: 338.

11. Maynard SJ, Szathmáry E (1995) The Major Transitions in Evolution. San Francisco: Freeman Press. pp: 346. 


\section{International Journal of Zoology and Animal Biology}

12. Szathmáry E, Maynard SJ (1995) The major evolutionary transitions. Nature 374: 227-232.

13. Eldredge N, Gould SJ (1972) Punctuated equilibria: an alternative to phyletic gradualism. TJM Schopf, pp: 82-115.

14. Gould S, Eldredge N (1977) Punctuated equilibria: the tempo and mode of evolution reconsidered. Paleobiology 3(2): 115-151.

15. Darwin C (1859) The Origin of Species by Means of Natural Selection, or Preservation of Favoured Races in the Struggle for Life; London: John Murray.

16. Margulis L (1981) Symbiosis in Cell Evolution. San Francisco: Freeman pp: 452.

17. Montagu A (1955) Time, morphology, and neoteny in the evolution of man. American Anthropologist 57(1): 13-27.

18. Neisser U, Boodoo G, Bouchard TJ, Boykin AW, Brody $\mathrm{N}$, et al. (1996) Intelligence: Knowns and unknowns. American Psychologist 51(2): 77-101.

19. Berwick RC, Chomsky N (2016) Why Only Us? MIT Press, Cambridge, MA, pp: 215.

20. DeBruine LM, Jones BC, Crawford JR, Welling LLM, Anthony CL (2010) The health of a nation predicts their mate preferences: cross-cultural variation in women's preferences for masculinized male faces. Proceedings of the Royal Society 277: 2405-2410.

21. Jones BC, Feinberg DR, Watkins CD, Fincher CL, Little AC, et al. (2012) Pathogen disgust predicts women's preferences for masculinity in men's voices, faces, and bodies. Behavioral Ecology 24: 373-379.

22. Thornhill R, Gangestad SW, Scheib JE (1999) Facial attractiveness, symmetry and cues of good genes. Proc Biol Sci 266(1431): 1913-1917.

23. DeBruine LM, Little AC, Jones BC (2012) Extending parasite-stress theory to variation in human mate preferences. Behavioral and Brain Sciences 35: 86-87.

24. Edward DA, Chapman T (2011) The evolution and significance of male mate choice. Trends Ecol Evol 26(12): 647-654.

25. David B (2016) Evolutionary Psychology: the New Science of Mind. New York: Routledge pp: 133-162.
26. David B (2016) Evolutionary Psychology, the New Science of Mind. New York: Routledge. pp: 163-176.

27. Ludvico LR, Kurland JA (1995) Symbolic or not-so symbolic wounds: The behavioral ecology of human scarification. Ethology and Sociobiology 16(2): 155172.

28. Antfolk J (2017) Age Limits: Men's and Women's Youngest and Oldest Considered and Actual Sex Partners. Evolutionary Psychology 15 (1).

29. Antfolk J, Salo B, Alanko K, Bergen E, Corander J, et al. (2015) Women's and men's sexual preferences and activities with respect to the partner's age: evidence for female choice. Evolution \& Human Behavior 36 (1): 73-79.

30. Lynn R (1999) New evidence for dysgenic fertility for intelligence in the United States. Soc Biol 46 (1-2): 146-153.

31. Lynn R, Marian VC (2004) New evidence of dysgenic fertility for intelligence in the United States. Intelligence 32 (2): 193-201.

32. Meisenberg G (2010) The reproduction of intelligence. Intelligence 38(2): 220-230.

33. Boutwell BB, Franklin TW, Barnes JC, Beaver K, Deaton R, et al. (2013) County-level IQ and fertility rates: A partial test of Differential- $K$ theory. Personality and Individual Differences 55(5): 547552.

34. Kanazawa S (2014) Intelligence and childlessness. Social Science Research 48(2014): 157-170.

35. Trefil J (2007) Who Were the Ancient Engineers of Egypt? Skeptical Briefs: 17(1).

36. May A (2016) Pseudoscience and Science Fiction. Springer pp: 133.

37. Whitehead AN (1929) Process and reality: an essay in cosmology. Cambridge University Press pp: 509.

38. Boltzmann L (1886) The Second Law of Thermodynamics. Ludwig Boltzmann: Theoretical physics and Selected writings, McGinness BD, et al. (eds), The Netherlands, 1974.

39. Schrödinger E (1944) What is Life? The Physical Aspect of the Living Cell. Cambridge University Press. 
40. Onsager L (1931) Reciprocal Relations in Irreversible Processes I and II. Phys Rev 38 (405): 2267-2279.

41. Prigogine I (1967) An Introduction to the Thermodynamics of Irreversible Processes. Wiley, New York.

42. Dewar R, Juretić D, Županović P (2006) The functional design of the rotary enzyme ATP synthase is consistent with maximum entropy production. Chem Phys Lett 430(1): 177-182.

43. Unrean P, Srienc F (2011) Metabolic networks evolve towards states of maximum entropy production. Metabolic Engineering 13(6): 666-673.

44. Zotin AI (1984) Bioenergetic trends of evolutionary progress of organisms. Thermodynamics and regulation of biological processes, Lamprecht I, et al. (eds), pp: 451-458.

45. Schneider ED, Kay JJ (1994) Life as a Manifestation of the Second Law of Thermodynamics. Mathl Comput Modelling 19(6-8): 25-48.
46. Michaelian K (2005) Thermodynamic stability of ecosystems. J Theor Biol 237(3): 323-335.

47. Michaelian K (2009) Thermodynamic Origin of Life. Earth Syst Dynam (2): 37-51.

48. Michaelian K (2011) Thermodynamic dissipation theory for the origin of life. Earth Syst Dynam 2(1): 37-51.

49. Michaelian K (2016) Thermodynamic Dissipation Theory of the Origin and Evolution of Life: Salient characteristics of RNA and DNA and other fundamental molecules suggest an origin of life driven by UV-C light, Printed by Create Space, Mexico City.

50. Michaelian K (2017) Microscopic dissipative structuring and proliferation at the origin of life. Heliyon 3(10): e00424.

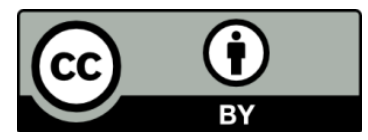

